\title{
Educação do campo e pedagogia social: interculturalidade em lutas coletivas por terra e educação
}

\author{
Erineu Foerste*; Bernd Fichtner**; José Wálter Nunes***; João Clemente de \\ Souza Neto****
}

Resumo. O artigo objetiva discutir Educação do Campo como prática de Pedagogia Social. As análises focam a problemática das lutas por terra e educação dos trabalhadores rurais, especialmente as Comunidades e Povos Tradicionais (Decreto 6.040/2010). Como a Educação do Campo trabalha as culturas e saberes dos trabalhadores rurais? Educação do Campo não é um conceito monovalente nem se restringe a processos de escolarização; pode ser definida como prática de interculturalidade (Fornet-Betancourt, 2001). Parte-se de abordagens investigativas sócio-históricas (Fichtner et al., 2013), para avaliação de documentos oficiais, reafirmando a educação enquanto direito dos cidadãos e dever do Estado. Práticas colaborativas interinstitucionais (Foerste, 2005) entre movimentos sociais, secretarias de educação, universidade etc. consideram povos, territórios, culturas e saberes tradicionais como dimensões articuladoras da construção coletiva de projetos pedagógicos da Educação do Campo como prática de Pedagogia Social.

Palavras-chave: educação do campo; pedagogia social; culturas e saberes tradicionais; parceria.

\section{EDUCACIÓN RURAL Y PEDAGOGÍA SOCIAL: INTERCULTURALIDAD EN LUCHAS COLECTIVAS POR LA TIERRA Y LA EDUCACIÓN}

Resumen. El objetivo de este artículo es discutir la Educación rural como práctica de Pedagogía Social. Los análisis enfocan la problemática de las luchas por la tierra y la educación de los trabajadores rurales, especialmente las Comunidades y Pueblos Tradicionales (Decreto 6.040 / 2010). ¿Cómo trabaja la Educación rural las culturas y los saberes de los trabajadores rurales? La Educación rural no es un concepto monovalente ni se restringe a procesos de escolarización; se puede definirla como una práctica de interculturalidad (Fornet-Betancourt, 2001). Se utilizan enfoques investigativos socio-históricos (Fichtner et al., 2013) para la evaluación de documentos oficiales, reafirmando la educación como derecho de los ciudadanos y deber del Estado. Prácticas colaborativas interinstitucionales

\footnotetext{
* Universidade Federal do Espírito Santo (UFES), Brasil.

** Universität-Siegen (UNISIEGEN), Alemania.

*** Universidade de Brasília (UB), Brasil.

**** Universidade Presbiteriana Mackenzie (UPM), Brasil.
} 
(Foerste, 2005) entre movimientos sociales, secretarías de educación, universidad, etc. consideran a los pueblos, territorios, culturas y saberes tradicionales como dimensiones articuladoras de la construcción colectiva de proyectos pedagógicos de la Educación en el Campo como práctica de Pedagogía Social.

Palabras clave: educación rural; pedagogía social; culturas y saberes tradicionales; asociaciones.

\section{RURAL EDUCATION AND SOCIAL PEDAGOGY: INTERCULTURALITY IN COLLECTIVE STRUGGLES FOR LAND AND EDUCATION}

Abstract. The article aims to discuss Rural Education as a practice of Social Pedagogy. Analyses focus on the problems of land and education struggles of rural workers, especially the Traditional Communities and Peoples (Decree 6.040/2010). How does Rural Education work the cultures and knowledge of rural workers? Rural Education is not a monovalent concept nor is it restricted to schooling processes; it can be defined as interculturality practice (Fornet-Betancourt, 2001). It is based on socio-historical research approaches (Fichtner et al., 2013) for the evaluation of official documents, reaffirming education as citizens' rights and the duty of the State. Interinstitutional collaborative practices (Foerste, 2005) among social movements, education departments, universities and so on, consider peoples, territories, cultures and traditional knowledge as dimensions that articulate the collective construction of pedagogical projects of the Rural Education as a practice of Social Pedagogy.

Keywords: rural education; social pedagogy; traditional cultures and knowledge; partnership.

\section{INTRODUÇÃO}

A I Conferência Nacional: Por uma Educação Básica do Campo, realizada em 1998 pelos movimentos sociais, foi apoiada pela Conferência Nacional dos Bispos do Brasil (CNBB), Fundo das Nações Unidas para a Infância (UNICEF), Organização das Nações Unidas para Educação, Ciência e Cultura (UNESCO) e universidades, entre outras entidades. Este evento pode ser considerado marco e culminância de lutas históricas dos movimentos campesinos por Reforma Agrária, demarcação de terras indígenas, regulamentação de territórios quilombolas e por uma educação diferenciada no campo. Resistências promovidas pelos trabalhadores à Ditadura Militar (1964 a 1985) e ao agronegócio marcam as organizações de base por direitos sociais coletivos.

Houve reconhecimento de Povos e Comunidades Tradicionais (PCT's): indígenas, quilombolas, pomeranos, extrativistas, ribeirinhos etc. (Brasil, 2010b), com fortalecimento de políticas públicas de Educação do Campo, indígena e quilombola nos últimos anos. A título de exemplo, citamos a criação 
do Programa Nacional de Educação na Reforma Agrária (PRONERA), que foi instituído como política pública pelo Decreto 7.352/2010 (Brasil, 2010a); ao mesmo tempo, oficializou-se a Comissão Nacional das Comunidades e Povos Tradicionais (CNPCT) pelo Decreto 6.040/2010 (Brasil, 2010b).

Os segmentos menos favorecidos da sociedade civil, genericamente denominados de classe trabalhadora, consideram tais medidas como conquistas de direitos sociais dos sujeitos campesinos e das águas e florestas. Os dispositivos legais publicados no Governo do Presidente Lula reconhecem lutas coletivas por justiça social. A educação em todos os níveis e modalidades é um destaque fundamental nesse movimento, com destaque para a educação popular (educação indígena, educação quilombola, Educação do Campo. Educação de jovens e adultos).

Ao lado destas conquistas sociais, os debates interinstitucionais pela construção e implementação de políticas públicas de demarcação de territórios (povos indígenas, quilombolas, pomeranos, sertanejos, ribeirinhos, sem-terra etc.) ganharam força. Assim, a Educação do Campo é uma prática social compreendida crescentemente como dimensão articuladora das reivindicações dos movimentos sociais, apoiados pela igreja, universidades, órgãos governamentais nacionais e internacionais entre outros.

Vivemos um tempo de retrocessos nas políticas sociais desde a tomada de poder pelo Michel Temer. Por isso se ressaltam denúncias de organizações da sociedade civil em relação às práticas crescentes de violência contra os campesinos. A impunidade de crimes desse tipo é enfrentada pelos movimentos sociais para que o judiciário cumpra seu dever na aplicação do aparato judicial no julgamento e condenação de criminosos contra o povo. Explicita-se a gravidade dos problemas enfrentados pelos Povos e Comunidades Tradicionais (PCT's) do campo, pela perda de importantes conquistas sociais com o avanço do agronegócio e o latifúndio. 0 risco permanente de perda de território, a falta de atendimento às demandas de educação, o fechamento de escolas, a omissão do Estado em relação às especificidades culturais e dos saberes dos sujeitos do campo, o desrespeito aos profissionais do ensino e abandono sistemático das escolas e consequente baixa qualidade do ensino no meio rural mobilizam movimentos organizados de resistência que culminam com a Articulação Nacional por uma Educação do Campo. Trata-se de reafirmar que as lutas coletivas dos trabalhadores do campo não se limitam à educação escolar em seu sentido estrito. Elas colocam ênfase na construção de projetos públicos de educação, em que a formação ao longo de toda a vida é um direito do cidadão e dever do Estado. 
Assim este artigo apresenta a seguinte organização: Introdução; Considerações sobre o Contexto; Educação do Campo como Prática de Pedagogia Social: Resistências ao Progresso e Desenvolvimento; Qual Educação?; Educação do Campo como Prática de Pedagogia Social; Questões para continuidade dos debates.

\section{CONSIDERAÇÕES SOBRE O CONTEXTO}

O governo nas suas diferentes esferas (municipal, estadual e federal) é pressionado pelos movimentos sociais organizados, para atender plenamente a demandas de Educação do Campo como direito social e dever do Estado. Desde seu surgimento na primeira metade dos anos 80, o Movimento Sem Terra, por exemplo, coloca a luta por educação pública do trabalhador do campo como uma a principal causa juntamente com a Reforma Agrária. Nos últimos anos, sobretudo a partir da criação do Programa Nacional de Educação na Reforma Agrária (PRONERA) em 1998 e, pelo Decreto 5.159/2004, da Secretaria de Educação Continuada, Alfabetização, Diversidade e Inclusão (SECADI), no interior do Ministério da Educação (MEC) em 2004 (Brasil), 2004), já se observam algumas conquistas importantes, que fazem avançar a construção de projetos de Educação do Campo, bem como de educação indígena e educação quilombola, fundamentados em pressupostos do trabalho e da pesquisa como princípios educativos e estão articulados às práticas sociais.

Em acampamentos e assentamentos da Reforma Agrária, em comunidades indígenas e quilombolas, por exemplo, implementaram-se, graças à persistência dos Povos e Comunidades Tradicionais (PCT's), programas de educação de crianças, jovens e adultos, na oferta de cursos técnicos profissionalizantes, na educação continuada de modo geral, na formação inicial e continuada de professores etc. Projetos como esses colocam uma questão importante, firmada a partir de debates acumulados nas experiências concretas de coletivos socais, pelo resgate das múltiplas identidades dos indivíduos que trabalham no campo: o trabalhador campesino é o sujeito da construção de outro projeto de campo, cujo embasamento é feito a partir da agricultura familiar agroecológica, para além do latifúndio e do agronegócio.

Isso significa, do ponto de vista teórico e prático, que o campo é uma construção coletiva no movimento permanente pela conquista da terra, cultivando a vida digna a cada dia. 0 trabalho coletivo e a prática da solidariedade fazem nascer projetos alternativos fundamentados em culturas e saberes tradicionais sem precedentes no campo, que fortalecem cada vez mais lutas históricas dos oprimidos, no sentido proposto por Paulo Freire (1970), 
por outras possibilidades de cultivo da terra e produção de educação como prática social, sem dicotomizar ser humano-natureza, para além de processos institucionalizados de escolarização.

A Constituição de 1988 já havia incorporado aspectos das lutas sociais pelo resgate da cidadania dos excluídos da cidade e do campo, com respeito às diferenças culturais, étnicas, religiosas e rejeição das diferenças sociais, que legitimam a distribuição desigual das riquezas. Debates enfatizam a importância da afirmação de direitos populares na construção e implementação de políticas públicas, em que a educação é um dos pilares fundamentais. Assim, a participação efetiva do povo na gestão pública, exercendo controle sistemático sobre os órgãos de governo, tornou-se uma conquista constitucional que precisava também se fazer presente em relação aos processos educativos formais no campo, desde a educação infantil até o nível universitário. Há que se fortalecer conquistas realizadas e ampliar atendimento às demandas de educação como política social pública.

Discussões que culminaram com a aprovação da Lei de Diretrizes e Bases da Educação Nacional (LDBN) n 9.394/96 apontam especificidades da Educação do Campo (conforme artigo 28), o que pressupõe outro tipo de prática educativa, que coloque no centro do processo pedagógico questões vividas pelos trabalhadores do campo, em suas lutas na produção de subsistência a partir do cultivo agroecológico da terra. Tal conquista, ainda que a duras penas, vem se concretizando aos poucos, graças à persistência e articulações de entidades de representação coletiva dos trabalhadores do campo, como: Movimento Sem Terra - MST, Confederação Nacional dos Trabalhadores na Agricultura (CONTAG), Movimento dos Pequenos Agricultores (MPA), Comissão Pastoral da Terra (CPT), Centros Familiares de Formação por Alternância (CEFAS), Federação dos Trabalhadores da Agricultura no Espírito Santo (FETAES), Comissão Nacional das Comunidades e Povos Tradicionais (CNPCT), entre outras.

O artigo 28 da LDBN levou o Conselho Nacional de Educação/Câmara de Educação Básica (CNE/CEB) a aprovar Parecer CNE/CEB n 36/2001 e Resolução CNE/CEB n 1/2002, instituindo Diretrizes Operacionais para a Educação Básica nas Escolas do Campo. Estes textos legais explicitam relevância do respeito à diversidade na igualdade, com ênfase não somente em processos formais de formação humana como prática social inclusiva. Nesse sentido, a Educação do Campo é tomada aos poucos oficialmente no país como prática social que não se constrói como oposição ao urbano ou às coisas da cidade; mas como devir e possibilidade concreta, articuladora de todos os seres humanos no processo de produção das condições de subsistência agroecológicas de todas as pessoas do campo e da cidade. 
$\mathrm{Na}$ atual conjuntura internacional, com o fortalecimento das formas perversas de exclusão geradas pelo neoliberalismo e globalização (lei da economia de mercado), os movimentos sociais redobram esforços de análise e de articulação. Crescem índices de empobrecimento do povo, aumentando diferença entre a classe detentora do capital e os trabalhadores da cidade e do campo. A degradação das condições de vida da população é galopante, elevando significativamente desigualdades sociais, que naturalizam a exclusão social.

A escola no campo (currículo oficial) reforça ainda a lógica de mercado na medida em que sua prática reproduz um modelo de desenvolvimento e progresso na agricultura que legitima o paradigma utilitarista de natureza das ciências modernas. Ignoram-se práticas alternativas de produção da vida no trabalho na terra, construídos concretamente no trabalho de Povos e Comunidades Tradicionais (PCT's), pois os governantes incentivam, priorizam com subsídios e incrementam o agronegócio. Os montantes de recursos públicos destinados a este modelo de desenvolvimento rural não têm se revertido, na mesma proporção, em benefícios sociais para os trabalhadores do campo. A riqueza, ainda que questionável na sua base de sustentabilidade ecológica, não tem sido socializada. Não há equidade social no modelo de desenvolvimento do agronegócio e do latifúndio.

\section{EDUCAÇÃO DO CAMPO COMO PRÁTICA DE PEDAGOGIA SOCIAL: RESISTÊNCIAS AO PROGRESSO E DESENVOLVIMENTO}

O projeto hegemônico de desenvolvimento nacional brasileiro das cidades e do campo coloca em questão pressupostos das lutas dos trabalhadores em geral, em detrimento de conquistas importantes para a consolidação de uma sociedade humanizada, sem injustiças sociais. Reforçam-se políticas que favorecem a hegemonia do capitalismo internacional, o que inviabiliza projetos populares e alternativos de produção material e simbólica com sustentabilidade do campo, em que a educação é um dos pressupostos fundamentais.

Pensar uma Educação do Campo a partir dos sujeitos do campo ou trabalhadores rurais exige desconstruir o paradigma hegemônico de desenvolvimento e de educação, imposto a eles pelo Estado. Lutas coletivas ressignificam práticas sociais e culturais a partir de outro conteúdo político-ideológico em que a agroecologia é eixo articulador. Nesse sentido em termos epistemológicos, no que consiste um projeto popular-libertador de educação? Em que pressupostos ele se baseia, quando se trata do binômio Educação do Campo? 
Um primeiro aspecto precisa ser realçado na análise desse quadro geral. 0 direito à educação constitui-se como marco legal inalienável e indispensável para o resgate da cidadania de um povo, no discurso oficial. A burguesia precisa legitimar sua agenda política e ideológica conservadora e oligárquica, por meio de reformas trabalhistas e da previdência, para dar sustentação ao projeto econômico da classe dominante numa nova ofensiva neoliberal. As lutas do povo por uma educação popular-libertadora, entretanto, colocam-se a serviço da construção de uma sociedade humanizada e democrática, que não coincide com o projeto burguês de educação na cidade e no campo.

Sendo assim, a Educação do Campo define-se como prática de Pedagogia Social; emerge da resistência coletiva dos sujeitos campesinos ao projeto hegemônico de educação escolar, regulado pelo Estado. Ela baliza-se antes por princípios inaugurais de base comunitária que estão se mostrando viáveis em experiências concretas de uma educação popular alternativa em assentamentos de reforma agrária (Programa Nacional de Educação na Reforma Agrária [PRONERA], 2004; Andrade et al., 2004). Gradativamente tais pressupostos alternativos na área de educação levaram a discussões coletivas pela superação de concepções equivocadas, pelas quais se consolidou na história do pensamento pedagógico burguês uma hierarquia de valoração entre a cidade e o campo, sobrepondo aquela a este.

Processos de engajamento ideológicos revolucionários, emanados de ações reflexivas e politicamente identificadas com os movimentos sociais dos trabalhadores rurais, colocam, a partir de novos patamares teórico-práticos, a relevância de transformações de base que favoreçam a superação de abordagens idealizadas do campo, reforçadas pelas políticas públicas das elites governantes e pela mídia de um modo geral (jornais, televisão, livros, filmes, músicas etc.). Um passo importante a se dar, não resta dúvida, é produção coletiva de críticas dos discursos midiáticos, que apresentam o campo como contexto em que prevalece abundância e não existem conflitos próprios da sociedade de classes. Mais do que, a construção de uma contra-ideologia, é uma luta concreta dos excluídos, que não pode ser descuidada. A Educação do Campo e da cidade é um dos projetos que pode contribuir de forma significativa nesse processo revolucionário de reconhecimento e valorização de identidades e culturas, diretamente articuladas aos saberes de Povos e Comunidades Tradicionais (PCT's).

Vale ressaltar, então, na perspectiva dos trabalhadores das cidades e do campo, que a abordagem da educação emancipatória/libertadora constituise como produção histórica, materializada por contradições explicitadas nos embates da sociedade de classes. Ao longo do tempo as elites criaram mecanismos que cerceiam aos trabalhadores do campo e das cidades acesso pleno 
às condições que garantem dignidade ao ser humano. A educação é um dos direitos negados aos trabalhadores ao longo da história brasileira. Posto isso ressalta-se que hoje se colocam condições concretas para reflexão e debates sobre Educação do Campo como produção coletiva de sujeitos que lutam pelo resgate do direito à fala de todos aqueles que se encontram hostilizados nas relações desiguais produzidas pela sociedade capitalista.

A Educação do Campo não comporta uma perspectiva compensatória, como querem os detentores do poder econômico nacional. Qual projeto de desenvolvimento do campo se pretende implantar com as políticas públicas de educação de nosso país? (Foerste, Schütz-Foerste \& Merler, 2013). Não podemos abordar a problemática da Educação do Campo focando o olhar nas questões da formação humana como se elas não estivessem articuladas com aspectos econômicos, sociais e culturais, permeadas por ideologias e disputas por hegemonia. Precisamos abordá-la como política social, num quadro complexo de ação governamental, em que políticas públicas de saúde, educação, agricultura, moradia, transporte etc. formam uma totalidade na promoção de todos os seres humanos. Trata-se de projetos que não se encontram dissociadas num conjunto de práticas sociais que se colocam no movimento pelo resgate da cidadania dos excluídos. Que significa, então, Educação do Campo nesse contexto?

A tarefa de sistematizar princípios norteadores para a construção de um projeto político de Educação do Campo constitui desafio que deve se pautar na reflexão a partir de uma história de lutas e discussões coletivas de diferentes segmentos de populações exploradas, ligados direta ou indiretamente aos movimentos sociais organizados do campo e da cidade. Refletir a respeito de uma escola emancipatória/libertadora, no sentido proposto por Paulo Freire (1970 e 1996), não exclui nem hierarquiza sujeitos; porém, busca incluí-los na medida em que todos são oprimidos na sociedade de classe e todos se libertam na luta pela superação das contradições das injustiças produzidas nos processos de produção, acumulação e distribuição desigual de bens materiais e simbólicos.

Elencamos a seguir alguns pontos para discussão, na tentativa de contribuir com debates partilhados com todos aqueles que acreditaram e continuam pensando que é possível em nosso país e na América Latina transformar a escola, garantindo no seu interior o encontro de muitas cores, muitas falas e narrativas, muitas histórias de vida, para a dignificação de todos. Esta é uma luta dos oprimidos do campo e dos oprimidos da cidade, por um projeto pedagógico popular-libertador de Educação do Campo e da cidade. 
Não se trata de pensar pelo povo do campo, na lógica das cidades, ou para ele, mas dialogando com suas histórias, memórias e narrativas, para compreender como participar de suas lutas, compartilhando sofrimentos, mas principalmente aprendendo com eles a cultivar práticas de humildade, de diálogo e resistências em favor da humanização de todas as pessoas. Assim podem florescer esforços coletivos de base para fazer nascer em toda a terra, em todos os lugares, o desejo de ocupar terra, aprendendo a escutá-la, ouvindo o que ela nos tem a dizer sobre como nos organizarmos para construir uma sociedade sem fome, sem injustiças étnicas, de gênero, religiosas etc.

\section{QUAL EDUCAÇ̃̃O?}

Discutir Educação do Campo pressupõe uma problematização de dispositivos legais. Em termos de legislação, o Brasil conta com significativos dispositivos, que podem fundamentar implementação de políticas públicas diferenciadas de Educação do Campo em atendimento às demandas dos trabalhadores rurais. Disponibilizam-se de instrumentos reguladores de Estado que servem de base no cenário nacional, para a construção de projetos alternativos de Educação do Campo, portanto, nas suas interfaces com os Povos e Comunidades Tradicionais (CPT's) (Indígenas, quilombolas, ribeirinhos, extrativistas, ciganos, pomeranos etc.).

Uma dessas ferramentas legais é Constituição de 1988. A regulamentação mais recente da Educação Brasileira se deu basicamente por meio da Lei de Diretrizes e Bases da Educação Nacional (LDBN) n 9.394/1996 de 20/12/1996. A Educação Indígena conta com dois dispositivos específicos: a) Parecer CNE/CEB n 14/1999 de 14/09/1999 em que se estabelecem Diretrizes Nacionais para o funcionamento das Escolas Indígenas; b) ResoIução CNE/CEB nº 03/1999 de 10/11/1999 - Institui Diretrizes Nacionais para o funcionamento das Escolas Indígenas. Com a Lei n 10.172/2001 foi aprovado o Plano Nacional de Educação (PNE) que foi substituído pela Lei $n^{\circ}$ 13.005, de 25 de junho de 2014. A Educação do Campo foi regulamentada com um parecer e uma resolução do Conselho Nacional de Educação (CNE), a saber: a) Parecer CNE/CEB n 36/2001 de 04/12/2001- Diretrizes Operacionais à Educação Básica nas Escolas do Campo e b) Resolução CNE/ CEB n 01/2002 de 03 de abril de 2002 - Institui Diretrizes Operacionais para a Educação Básica nas Escolas do Campo. Avanço importante foi conquistado na regulamentação dos temas afro-brasileiros na educação escolar com aprovação de quatro marcos normativos: a) Lei $n^{\circ} 10.639 / 2003$ de 09/01/2003 - Estabelece Inclusão de Temas da Cultura Afro-brasileira no Currículo Escola; b) Parecer CNE/CEB n 03/2004 de 10/03/2004 - Diretrizes Curriculares Nacionais para a Educação das Relações Étnico-Raciais e para 
- Ensino de História e Cultura Afro-Brasileira e Africana; c) Resolução CNE/ CEB n ${ }^{\circ}$ 01/2004 de 17/06/2004 - Institui Diretrizes Curriculares Nacionais para a Educação das Relações Étnico-Raciais e para o Ensino de História e Cultura Afro-Brasileira e Africana e d) Lei $n^{\circ}$ 11.645/2008 - Estabelece o Ensino de História e Cultura Indígena e Afro-Brasileira no Currículo Escolar. Discussões teórico-práticas acumuladas sobre Pedagogia da Alternância (PA) serviram de base para se aprovar o Parecer CNE/CEB n 01/2006 de 01/02/2006 - Recomenda a Adoção da Pedagogia da Alternância (PA) em Escolas do Campo. Durante o Governo do Presidente Lula, estabeleceram-se importantes interlocuções com segmentos excluídos das esferas de poder e decisão, para definir políticas públicas de valorização de culturas e saberes dos Povos Comunidades Tradicionais (PCT's), como: Indígenas, quilombolas, ribeirinhos, extrativistas, ciganos, pomeranos etc. A culminância desses processos se deu com a publicação do Decreto n ${ }^{\circ}$ 6.040/2007 de 07/02/2010, pelo qual se Institui Política Nacional Sustentável dos Povos e Comunidades Tradicionais (PCT's).

Discussões acumuladas no cenário nacional, até o momento, apontam para a construção coletiva do projeto Político e Pedagógico da Educação do Campo, para se considerar culturas e saberes dos Povos e Comunidades Tradicionais (PCT's); emergem e se consolidam nos processos de produção das existências materiais e simbólicas de Indígenas, Quilombolas, Pomeranos, Ribeirinhos etc. Em face disso, pergunta-se: Como a legislação contribui ou pode contribuir para implementação de processos educativos do campo, para fortalecimento das lutas dos campesinos por direitos sociais coletivos? Vale ressaltar que o conceito de campo não é monolítico, uma vez que a produção de subsistência da agricultura familiar do minifúndio (propriedades de 25 ha. ou menos) não coincide com o modelo ganancioso de desenvolvimento do agronegócio promovido pelo latifúndio.

Por outro lado, é preciso considerar uma significativa diversidade de territórios e comunidades produtivas em áreas de pequena extensão que organizam arranjos produtivos específicos a partir de características culturais muito próprias, como é o caso dos indígenas, quilombolas e extrativistas. A esses processos produtivos, que podemos definir como alternativos na sua concepção e prática, estão referenciados culturas e saberes alternativos e não raro invisibilizados pela correlação de forças do mundo do mercado capitalista. Este é o caso, por exemplo, dos povos tradicionais das florestas (extrativistas da Amazônia), quebradeiras de coco babaçu, catadeiras de mangaba, floristas, faxinalenses, povos ribeirinhos, povos indígenas, comunidades quilombolas, comunidades pomeranas, entre outros. 
Desse modo a Educação do Campo considera, entre outros aspectos fundantes de uma pedagogia alternativa: sujeitos do campo; economia familiar agroecológica; povos tradicionais em seus respectivos territórios; saberes da terra; trabalho e pesquisa como princípio educativo; cultura como produção social da vida; interculturalidade; interdisciplinaridade como construção de conhecimento coletivo e engajado; cooperativismo e/ou associativismo como construção dialógica e política de participação; sustentabilidade etc. As propostas pedagógicas de Educação do Campo orientam-se a partir de pressupostos, tais como: sujeitos do campo, saberes da terra, territórios e povos tradicionais do campo, trabalho coletivo, pesquisa, agricultura familiar, sustentabilidade, culturas, identidades e interculturalidade, participação cidadã, diálogo, interdisciplinaridade, formação inicial e continuada etc., enfim, Educação do Campo como prática de Pedagogia Social.

\section{EDUCAÇÃO DO CAMPO COMO PRÁTICA DE PEDAGOGIA SOCIAL}

Partindo do exposto até aqui, a seguir faremos uma abordagem introdutória sobre alguns conceitos básicos e fundamentais para a Educação do Campo como prática de Pedagogia Social, tais como: campo, interculturalidade, agricultura familiar, sustentabilidade, agroecologia e poiesis.

\subsection{Sobre campo}

Parte-se da concepção de campo como espaço coletivo de construção social, econômica e cultural nos seus modos de produzir bens de consumo materiais e simbólicos. O campo não se define como ente geográfico ou cultural abstrato e isolado das correlações de poder no contexto nacional e internacional. Comunidades e Povos Tradicionais (PCT's) (indígenas, quilombolas, pomeranos, pescadores, ribeirinhos, extrativistas das florestas etc.) diferenciam-se entre si. Para eles o trabalho na terra humaniza as pessoas e a terra, ao ser cultivada, deixa-se humanizar. Este movimento não é linear nem se repete entre os territórios campensinos. Assim os povos tradicionais do campo constroem culturas e identidades próprias, o que não significa que estejam isolados ou que sejam autônomos em relação ao resto mundo. Território é uma dimensão central nesse debate.

O campo como território é marcado pelo trabalho humano e pela diversidade cultural. Há muitas formas de organizar os arranjos produtivos, com lógicas e estratégias próprias de sustentabilidade. Assim território "é espaço emancipatório quando associado à construção da democracia e de 
solidariedade de lutas pelo direito à terra, à educação, à saúde, à organização da produção e pela preservação da vida" (Secretaria de Educação Continuada, Alfabetização, Diversidade e Inclusão [SECADI], 2008, p. 27).

A palavra campo não é utilizada aqui em oposição à ideia de urbano. O termo campo deve ser tomado com sentido peculiar e diverso, não mais como sinônimo de "atraso". Há que se resgatar o campo como lócus de produção de subsistência importante presente ao longo de toda a história da humanidade, estabelecendo condições de vida para aqueles que cultivam a terra e vivem do trabalho da terra. Nesse sentido é preciso resgatar culturas e identidades dos trabalhadores do campo. Isso significa afirmar que os conhecimentos acumulados pelos povos campesinos contribuem para impulsionar a construção coletiva de projetos alternativos a partir de comunidades sustentáveis.

Partindo disso, então, pode-se falar de uma Educação do Campo diferenciada, que leve em consideração especificidades das demandas de formação dos trabalhadores do campo, partindo da noção de diversidade e pluralidade. Compreende-se que as políticas públicas devem atender às necessidades de projetos pedagógicos que emanam dos interesses daqueles que trabalham na terra e vivem no campo, sem estabelecer dicotomias com o urbano e as cidades em geral.

\subsection{Sobre interculturalidade}

Os trabalhadores rurais produzem culturas e saberes a partir do trabalho na terra. Genericamente os territórios campesinos são espaços geográficos e culturais em que vivem Povos Indígenas, Povos Quilombolas, Povo Pomerano, Extravistas, Ribeirinhos, Assentados de Reforma Agrária etc. Esses coletivos apresentam culturas e saberes específicos. Em suas organizações coletivas, a Comissão Nacional de Povos e Comunidades Tradicionais (CNPCT), o Movimento de Pequenos Agricultores (MPA), o Movimento Trabalhadores Rurais Sem Terra (MST), ente outros, indicam lutas com organização de base por direitos sociais, como: direito ao território, direito à educação, direito à saúde, direito ao saneamento básico etc.

A grande diversidade de culturas e saberes entre essas populações campesinas motivou debates pela articulação de movimentos para promoção do diálogo entre elas. Objetiva-se construir pautas de lutas coletivas por direitos sociais negados na correlação de forças na sociedade de classes, onde a distribuição de bens culturais e materiais gera grandes desigualdades e injustiças. A prática do diálogo, segundo Paulo Freire (1970), favorece a busca de pontos de convergência na diversidade. 
Por outro lado, o capitalismo tem gerado concentração de riquezas por meio de processos produtivos que geram exploração dos trabalhadores. 0 projeto de progresso e desenvolvimento burguês hegemônico, além do mais, revela-se inviável, porque oprime e violenta as pessoas e gera destruição da natureza, com grandes desequilíbrios ambientais. A concentração de terras nos latifúndios é uma consequência disso, expulsando para as periferias urbanas, populações que sempre viveram no campo. Os mais atingidos são as Comunidades e Povos Tradicionais.

O projeto de produção dessas populações campesinas alinha-se com a agroecologia e a sustentabilidade. Assim, promovem resistências às elites econômicas e ao agronegócio. Pelo diálogo na diversidade cultural, produzem uma epistemologia que, no dizer de Shiraishi Neto e Araújo (2015) e Nascimento Jr. (2016), pode ser denominado de bien vivir. Assim promovem resistências do projeto capitalista e contribuem para produção material e simbólica da existência humana com processos alternativos para construção de outra hegemonia. Para Gramsci (1977) a burguesia construiu um projeto de hegemonia para reproduzir o status quo e manter o poder econômico. De nossa parte, os trabalhadores rurais, ao dialogarem na diversidade cultural, considerando os diversos Comunidades e Povos Tradicionais que a compõem, não só produzem uma hegemonia alternativa e diferenciada, como legam uma epistemologia de como produzir com sustentabilidade.

Portanto, os fundamentos da interculturalidade (Fornet-Betancourt, 2001) remetem a um movimento que se caracteriza como articulação política e cultural na diversidade, para promover resistência e lutas por uma outra hegemonia. No caso dos trabalhadores rurais, a agricultura familiar como prática agroecológica com sustentabilidade objetiva superar a ganância do capital para promover uma concepção de processos produtivos pelos quais todos tenham o suficiente para viver bem.

\subsection{Sobre agricultura familiar, sustentabilidade e agroecologia}

Um projeto polpular-libertador de Educação do Campo, intrinsecamente articulado com as lutas dos trabalhadores do campo, conforme Freire (1970 e 1996), parte do pressuposto de que a ideia de desenvolvimento precisa ser problematizada e ressignificada. No âmago deste projeto educativo está o princípio da valorização da Vida, não somente no sentido de sua preservação romântica, ingênua e burguesa, muito presente nos discursos ambientalistas, mas também de sua reprodutibilidade. A dicotomia homem versus natureza perde significado, na medida em que a Terra é a mãe terra, que abriga a todos e que precisa ser cuidada e não explorada para atender a interesses de acumulação de riquezas em detrimento da Vida como produção 
histórica e cultural. Temos neste debate uma outra racionalidade para definir o homem e a natureza. Articulados aos Povos e Comunidades Tradicionais (PCT's) em suas lutas por terra e educação, trabalhadores rurais chegaram a essa compreensão, porque são capazes de refletir sobre a condição humana no mundo, sobre nossas ações, enfim sobre nossos modos de estar e ser em relaç.

Não há como ser de outro modo, uma vez que o ritmo do desenvolvimento capitalista nos desafia a pensar outras perspectivas de relação do homem com a natureza, menos predatórias, que estejam articuladas com possibilidades concretas de sustentabilidade a partir de contextos específicos em que nos encontramos. Cabe-nos perguntar como vemos o meio-ambiente e como nos relacionamos com a natureza a partir do contexto em que produzimos nossa existência. Que saberes acumulamos sobre nós e a natureza e que usos fazemos desse conhecimento? Faz sentido também questionar a respeito das possibilidades que produzimos para que todos tenham acesso de forma igual e justa a bens materiais e culturais, sem reforçar práticas de exclusão e/ou de autoritarismo, através da dominação de grupos minoritários, detentores do poder econômico e político, sobre as populações menos favorecidas.

Compreender o campo como território de formação de pessoas, de interações sociais e econômicas implica uma concepção diferenciada das relações dos trabalhadores dos diferentes territórios do campo com a terra e com a sociedade como um todo no processo de produção e distribuição de bens materiais e simbólicos. Nesse âmbito identifica-se agroecologia como criação dos trabalhadores do campo e das cidades nas lutas de resistência ao processo produtivo capitalista, que separa a força do trabalho e os meios de produção.

O debate sobre agricultura familiar, sustentabilidade e agroecologia constitui-se como alternativa dos trabalhadores ao projeto hegemônico de desenvolvimento, que tem gerado injustiças sociais e exclusão, ao mesmo tempo em que fortaleceu historicamente a exploração predatória da natureza por grupos econômicos que se revezam no poder. A sustentabilidade fundamenta uma forma diferenciada de relação do homem com a natureza, favorecendo a produção de conhecimentos que antes pareciam ter pouco significado ou eram considerados secundários, pois não serviam para a acumulação de riquezas. Trata-se, por exemplo, de pensar e produzir a vida na perspectiva da poiesis, a partir da qual do ser humano busca um novo sentido para si, na sua relação com os outros e com a natureza. 


\subsection{Sobre prática da poiesis}

A Educação do Campo exige posturas de risco, de engajamento pela construção do novo, rejeitando todas as formas de preconceito. Por isso não se pauta simplesmente na transmissão e assimilação de conhecimentos sistematizados. Nega a imposição de cânones, rediomensionando-os a partir dos saberes dos camponeses e dos saberes que estes demandam da escola para fortalecer lutas pela humanização do campo e da cidade. Tampouco a Educação do Campo fundamenta-se numa perspectiva espontaneísta, segundo a qual o ato de ensinar e aprender é a arte de tirar de dentro da pessoa aquilo que já está latente em todos os seres humanos, valorizada pelos defensores da educação essencialista inspirada em Platão. Educação do campo é práxis do movimento e contradição, com auto-crítica, para apurar, numa postura permanente de reflexão, o olhar a novas leituras, articuladoras de práticas de interpretação e transformação coletiva do mundo, este referido a saberes, tempos e lugares das lutas dos oprimidos.

\section{QUESTÕES PARA CONTINUIDADE DOS DEBATES}

A Educação do Campo como prática do diálogo intercultural (Foerste e Schütz-Foerste, 2017), mobiliza-nos para a construção coletiva de outra educação, que não fica restrita ao espaço escolar. A Educação do Campo é uma prática de Pedagogia Social construída nas lutas coletivas concretas dos movimentos sociais do campo por Reforma Agrária, com demarcação e regulamentação de territórios dos Povos e Comunidades Tradicionais (PCT's).

Consolidam-se movimentos articulados que promovem a diversidade cultural com mobilização de pessoas, coletivos sociais, movimentos sociais, instituições etc. para o diálogo na diferença cultural. São práticas de interculturalidade construídas e produzidas a partir da dialética dos movimentos coletivos, em que sujeitos históricos autônomos são capazes de ler o mundo, interpretar a realidade a partir de contradições das relações do homem com a natureza e dos seres humanos com outros seres humanos. A produção das condições materiais e simbólicas de existência de todas as pessoas e busca incansável de um mundo mais digno e humanizado são dimensões indissociáveis da Educação do Campo.

Nesse sentido, a Educação do Campo não se encontra acabada, mas é reinventada a cada dia, como prática de interculturalidade, com promoção de diálogos entre culturas e saberes convergentes; assume-se como prática precária e sempre incompleta, porque se articula como resistência ao projeto hegemônico de educação ditado pelas elites nacionais e internacionais. Ela 
não dicotomiza cidade e campo nem sujeito-natureza. A humanização do homem pressupõe humanização da natureza a partir de práticas de agroecologia na diversidade.

A Educação do Campo promove relações entre EU com o OUTRO (seres humanos- natureza-seres humanos), marcadas pela problematização permanente das culturas. Por isso é uma ação revolucionária e libertadora, pelas quais os sujeitos se reconhecem precários e históricos, pois admitem que os resultados de nossas lutas precisam ser cultivados e reinventados sempre. Reverência de cada pessoa frente à vida e à natureza define-se como movimento e pilar básico, os quais encontra na revolta contra todos os tipos de agressão à terra e todos os tipos de injustiças produzidas pela dominação humana as condições concretas para a produção histórica da Educação do Campo como prática intercultural de Pedagogia Social. Assim solidariedade promove engajamento dos sujeitos por aqueles que são humilhados e excluídos, desafiando a todos que exercem opressão sobre os outros a se libertarem de sua condição desumanizadora nessa relação de dominação com seus semeIhantes e consigo mesmos (Freire, 1970 e 1996). É libertação da Terra do agronegócio e do latifúndio, para produzir igualdade social e dignidade humana.

Podemos denominar, então, essa forma de educação como revolta dialógica intercultural, pela qual são impulsionadas reflexões e atitudes de esperança e alegria. A construção de novas alternativas sociais leva a reflexões sobre o respeito à vida e o direito à liberdade. Essa praxis educativa podemos denominar de Educação do Campo como prática de Pedagogia Social.

\section{BIBLIOGRAFIA}

Andrade, M. R. et al. (2004). A educação na Reforma Agrária em perspectiva; uma avaliação do PRONERA. Brasília: INCRA/PRONERA/Ação Educativa.

Brasil (2008). Projovem-campo saberes da terra. Recuperado de: http://www.dominiopublico. gov.br/download/texto/me4572.pdf.

Brasil (2004). Secretaria de Educação Continuada, Alfabetização, Diversidade e Inclusão. Recuperado de: http://portal.mec.gov.br/arquivos/pdf/d5159.pdf.

Brasil (2010a). Programa Nacional de Educação na Reforma Agrária. Recuperado de: http:// www.planalto.gov.br/ccivil_03/_ato2007-2010/2010/decreto/d7352.htm.

Brasil. (2010b). Comissão Nacional de Comunidades e Povos Tradicionais. Recuperado de: http://www.planalto.gov.br/ccivil_03/_ato2007-2010/2007/decreto/d6040.htm.

Foerste, E. (2005). Parceria na formação de professores. São Paulo: Cortez. 
Foerste, E. e Schütz-Foerte, G. M. (Org.) (2017). Educação do campo: diálogos interculturais. Curitiba: Appris.

Foerste, E., Schütz-Foerste, G. M. \& Merler, A. (Org.) (2013). Educação do campo: Diálogos interculturais em terras capixabas. Vitória: Edufes.

Fornet-Betancourt, R. (2001). Transformación intercultural de la filosofia. Bilbao: Editorial Desclée de Brouwer.

Freire, P. (1970). Pedagogia do oprimido. São Paulo: Paz e Terra.

Freire, P. (1996). Pedagogia da autonomia. São Paulo: Paz e Terra.

Nascimento Jr, W. dos R. (2016). O paradigma do "vivir bien" no estado plurinacional da Bolívia como referente para a construção de políticas públicas emancipatórias. Revista Brasileira de Políticas Públicas e Internacionais, v.1, n.1, Jun-Ago/2016, pp. 212-234.

Pronera. (2004). Pesquisa de avaliação do Programa Nacional de Educação na Reforma Agrária. Brasília: INCRA/PRONERA.

Shiraishi Neto, J. e Araújo, M. A. T. (2015). "Buen vivir": notas de um conceito constitucional em disputa. Recuperado de: http://periodicos.unifor.br/rpen/article/viewFile/2886/pdf. 
